\title{
UMA REFLEXÃO DA EDUCAÇÃO ESPECIAL A PARTIR DAS POLIITICAS PÚBLICAS EDUCACIONAIS BRASILEIRAS
}

\section{A REFLECTION OF SPECIAL EDUCATION FROM BRAZILIAN EDUCATIONAL PUBLIC POLICIES}

\author{
UNA REFLEXIÓN DE LA EDUCACIÓN ESPECIAL DE LAS \\ POLÍTICAS PÚBLICAS EDUCATIVAS BRASILEÑAS
}

\author{
João Carlos Bittencourt Damasceno' \\ jcbd@ymail.com \\ Douglas Junio Fernandes Assumpção \\ rp.douglas@hotmail.com
}

\section{RESUMO}

Este artigo tem como objetivo realizar uma reflexão da Educação Especial a partir do desenvolvimento das políticas públicas brasileiras para a Educação Inclusiva. A relevância da discussão se estabelece pela compreensão em considerar como os aspectos políticos, educacionais e ideológicos do contexto brasileiro interferem diretamente na formação dos professores e no aprendizado dos alunos e das alunas com deficiências, altas habilidades e/ou superdotação e transtornos globais do desenvolvimento. Para tanto, como aporte teórico, este trabalho utilizou os estudos de Selma Matos \& Enicéia Mendes (2014), Josiane Torres \& Enicéia Mendes (2018/2019), Marcos Mazzotta (2011), dentre outros. A metodologia adotada foi a revisão da literatura com a utilização de fontes que tragam informações e credibilidade à pesquisa, agregando, com isso, cunho científico e crítico ao estudo. Diante disso, como conclusão, percebeu-se que discorrer sobre a educação especial e o processo de inclusão envolve, necessariamente, refletir sobre as políticas públicas educacionais inclusivas que buscam fortalecer efetivamente o direito à educação dos/das educandos/das, a uma formação de qualidade aos professores, bem como a uma democratização de acesso e permanência na escola por partes desses/as alunos/as.

PALAVRAS-CHAVE: POLÍTICAS PÚBLICAS; EDUCAÇÃO ESPECIAL; EDUCAÇÃO INCLUSIVA; POLÍTICA NACIONAL DE EDUCAÇÃO ESPECIAL.

\section{ABSTRACT}

This article aims to reflect on Special Education based on the development of Brazilian public policies for Inclusive Education. The relevance of the discussion is

1 Secretaria Estadual de Educação do Pará (Seduc) / Secretaria Municipal de Educação de Ananindeua (Semed). 
DAMASCENO, JCB; ASSUMPÇÃO, DJF. Uma reflexão da educação especial a partir das políticas públicas educacionais brasileiras. Revista @mbienteeducação. São Paulo: Universidade Cidade de São Paulo, v. 13, n. 2, p. 216-231 Mai/Ago 2020.

established by understanding how the political, educational and ideological aspects of the Brazilian context directly interfere in the training of teachers and in the learning of students with disabilities, high skills and / or giftedness and global developmental disorders. Therefore, as a theoretical contribution, this work used the studies of Selma Matos \& Enicéia Mendes (2014), Josiane Torres \& Enicéia Mendes (2018/2019), Marcos Mazzotta (2011), among others. The methodology adopted was to review the literature using sources that bring information and credibility to the research, thus adding scientific and critical features to the study. Therefore, as a conclusion, it was realized that talking about special education and the inclusion process necessarily involves reflecting on inclusive educational public policies that seek to effectively strengthen the right to education of students, to the formation of quality to teachers, as well as democratization of access and permanence in school by parts of these students.

KEYWORDS: PUBLIC POLICY; SPECIAL EDUCATION; INCLUSIVE EDUCATION; NATIONAL SPECIAL EDUCATION POLICY.

\section{RESUMEN}

Este artículo tiene como objetivo reflexionar sobre la educación especial basada en el desarrollo de políticas públicas brasileñas para la educación inclusiva. La relevancia de la discusión se establece al comprender cómo los aspectos políticos, educativos e ideológicos del contexto brasileño interfieren directamente en la capacitación de maestros y en el aprendizaje de estudiantes con discapacidades, altas habilidades y / o superdotados y trastornos del desarrollo global. Por lo tanto, como contribución teórica, este trabajo utilizó los estudios de Selma Matos y Enicéia Mendes (2014), Josiane Torres y Enicéia Mendes (2018/2019), Marcos Mazzotta (2011), entre otros. La metodología adoptada fue revisar la literatura utilizando fuentes que aporten información y credibilidad a la investigación, agregando así características científicas y críticas al estudio. Por lo tanto, como conclusión, se dio cuenta de que hablar sobre educación especial y el proceso de inclusión implica necesariamente reflexionar sobre políticas públicas educativas inclusivas que buscan fortalecer efectivamente el derecho a la educación de los estudiantes, a la formación de calidad para los docentes, así como la democratización del acceso y la permanencia en la escuela por parte de estos estudiantes.

PALABRAS CLAVE: POLÍTICASPÚBLICAS; EDUCACIÓNESPECIAL; EDUCACIÓN INCLUSIVA; POLÍTICA NACIONAL DE EDUCACIÓN ESPECIAL.

\section{INTRODUÇÃO}

A Educação Especial no Brasil apresenta, em sua proposta, políticas públicas que buscam atender, de forma igualitária, os indivíduos da sociedade e, principalmente, 
DAMASCENO, JCB; ASSUMPÇÃO, DJF. Uma reflexão da educação especial a partir das políticas públicas educacionais brasileiras. Revista @mbienteeducação. São Paulo: Universidade Cidade de São Paulo, v. 13, n. 2, p. 216-231 Mai/Ago 2020.

as alunas e os alunos com deficiências, transtornos globais e altas habilidades e/ ou superdotação, no ensino básico regular e no ensino superior. Com isso, existem hoje documentos oficiais do Estado que direcionam o sistema de ensino desenvolvido no país, bem como as diretrizes e ações que devem ser contempladas nas escolas brasileiras.

Tais documentos oficiais, ao longo do percurso histórico e político do Brasil, sofreram mudanças em seus conteúdos e proposições. As alterações foram marcadas por novas propostas para as práticas pedagógicas e novos processos de ensinoaprendizagem, decorridas pela mudança social, política e educacional pelas quais a sociedade passou e passa ainda hoje.

Avanços e retrocessos fazem parte da história política do país. No caso da Educação Especial, as suas principais referências estão na Lei de Diretrizes e Bases da Educação Nacional (LDB 9394/96) e na Política Nacional de Educação Especial na Perspectiva da Educação Inclusiva (PNEEPEI 2008).

Os dois documentos são hoje os pilares para referenciar a Educação Especial no país. Por isso, este artigo tem como proposta realizar uma reflexão da educação Especial a partir do desenvolvimento das políticas públicas brasileiras para a Educação Inclusiva.

Desta forma, o processo metodológico centra-se na revisão de literatura e análise da LDB (9394/96) e da PNEEPEI (2008) como suportes para o desenvolvimento educacional do Brasil. Assim, joga-se um olhar, nesta pesquisa, dos estudos das narrativas de (CLANDININ e CONNELLY, 2011, p.18) discorrendo que a "verdadeira pesquisa narrativa é um processo dinâmico de viver e contar histórias, e reviver e recontar histórias, não somente aquelas que os participantes contam, mas aquelas também dos pesquisadores".

Nota-se que o texto, neste caso a LDB, a PNEEPEl e a experiencia dos pesquisadores, trata-se de um objeto analítico capaz de transpor informações e uma vez agregado ao conhecimento e a experiência do pesquisador legitima a análise a caracterizando como uma autobiografia, que Clandinin e Connelly, (2011 p.114) relatam que é sempre uma representação, um recontar, uma reconstrução particular da narrativa de um determinado sujeito. Trazendo para pesquisa uma proposta de analisar o objeto sob olhar crítico dos pesquisadores ampliando a possibilidade de realizar uma reflexão da educação especial a partir das políticas públicas educacionais brasileiras

Através desta proposta metodológica pode-se obter um suporte analítico, possibilitando ao/a pesquisador/a utilizar fontes que tragam informações e credibilidade ao estudo, agregando fontes de cunho científico e crítico, como teses, dissertações 
DAMASCENO, JCB; ASSUMPÇÃO, DJF. Uma reflexão da educação especial a partir das políticas públicas educacionais brasileiras. Revista @mbienteeducação. São Paulo: Universidade Cidade de São Paulo, v. 13, n. 2, p. 216-231 Mai/Ago 2020.

e artigos e documentos, como leis, políticas, decretos. (SÁ-SILVA; ALMEIDA; GUINDANI, 2009, p. 6).

\title{
POLÍTICAS PÚBLICAS NO ÂMBITO DA EDUCAÇÃO ESPECIAL
}

De acordo com Mazzotta (2011), o marco inicial das políticas públicas voltadas para a Educação Especial no Brasil se deu com a promulgação da LBD 9.394/96, em sua primeira versão Lei $n^{\circ} 4.024 / 61$. No artigo 88, apontava o direito dos excepcionais à educação, garantindo a integração desses alunos e dessas alunas no sistema geral de educação nacional.

O contexto político da promulgação desta Lei se refere à ditadura militar, e nele a participação popular era limitada e impedia que a coletividade apresentasse suas demandas ao poder público. Tal fato colaborava para que as elaborações das políticas públicas fossem realizadas sem considerar as demandas populares, além de atender apenas ao poder público e às iniciativas privadas.

Isso está ilustrado no artigo 89 desta mesma Lei, garantindo que as instituições particulares que atendiam os "excepcionais" tivessem incentivos como empréstimos e subvenções. Vê-se com isso que o estado, por meio das políticas públicas, atendia as necessidades de instituições privadas em detrimento das instituições públicas, gerando com isso um acesso e permanência de ensino menos igualitários.

\begin{abstract}
A construção de uma sociedade inclusiva torna-se fundamental para a consolidação e desenvolvimento do estado democrático, em que a educação inclusiva é uma parte integrante e essencial. Assim, o princípio da inclusão se globaliza, as teorias e práticas inclusivas passam a ser defendidas em muitos países, inclusive no Brasil. (MATOS; MENDES, 2014, p. 39).
\end{abstract}

Tal questão é refletida no contexto educacional do país dessa época, de modo que havia necessidades significativas da população para realizar alterações no processo de ensino-aprendizagem do público-alvo da educação especial de forma mais igualitária e democrática possível, mas mesmo com os espaços de fala minimizados a sociedade começava a exigir seus direitos na educação.

Cada vez mais se fazia necessário a reestruturação dos currículos das escolas, nas diversas formas de avaliação, na qualificação e formação continuada dos professores tanto da educação especial quanto do ensino comum. As mudanças também previam alterações nas estruturas físicas das escolas e dos espaços sociais aos quais as pessoas com deficiência usavam. Previa-se uma "adoção de uma política educacional mais democrática”. (MATOS; MENDES, 2014, p. 39). 
DAMASCENO, JCB; ASSUMPÇÃO, DJF. Uma reflexão da educação especial a partir das políticas públicas educacionais brasileiras. Revista @mbienteeducação. São Paulo: Universidade Cidade de São Paulo, v. 13, n. 2, p. 216-231 Mai/Ago 2020.

Seguindo as mudanças das políticas públicas de educação especial, outra versão da LDB 9.394/96 que influenciou foi a Lei $n^{\circ} 5.692 / 71$ cuja redação foi alterada no ano de 1982, passando a ser registrada como a Lei $n^{\circ} 7.044 / 82$, esta, por sua vez, fixava diretrizes e bases para o ensino básico a fim de proporcionar aos/às educandos/as formação necessária para desenvolver suas potencialidades como elemento de autorrealização, preparação para o trabalho e para o exercício consciente da cidadania. (MAZZOTTA, 2011, p. 73).

Ainda de acordo com a Lei 5.692/71, o Conselho Federal de Educação esclareceu sobre o seu entendimento a respeito do artigo $9^{\circ}$, no qual afirmava que o tratamento especial não poderia excluir o tratamento regular na vida dos alunos $e$ das alunas excepcionais. O entendimento do Conselho era de que, a partir desta Lei, a "educação dos excepcionais" se tornasse uma educação escolar, garantindo para eles/as uma linha de escolarização.

E em 1977, foi lançada a Portaria Interministerial $n^{\circ} 477$, de 11 de agosto, pelos Ministérios da Educação, da Cultura e da Previdência e Assistência Social. Esta Portaria regulamentava diretrizes básicas para o atendimento dos chamados excepcionais, destacando alguns objetivos, dentre eles: ampliar o atendimento médicopsicossocial e educacional dos excepcionais, e continuar oferecendo reabilitação e educação a eles.

Avançando para o ano seguinte, em 1978, o atendimento educacional especializado foi contemplado pela Portaria Interministerial $n^{\circ} 186$, em que a Educação Especial do país deveria organizar-se de forma integrada, contemplando ações médicas, psicológicas e assistenciais aos excepcionais, visando com isso um atendimento global e diferenciado.

Na verdade, é preciso reconhecer a dificuldade de conciliar um modelo clínico ou médico-psicológico para a avaliação e diagnóstico da excepcionalidade, com um modelo educacional para atendimento escolar. A utilização de um diagnóstico classificatório para fins de encaminhamento e colocação escolar tem se constituído tarefa complexa no campo da educação especial. (MAZZOTTA, 2011, p. 79).

Isso nos mostra que a Educação Especial era vista como um processo corretivo e preventivo que tinha como base a questão médica, clínica e psicológica. Ou seja, as pessoas com deficiência eram vistas como pacientes, e não como alunos e alunas com potenciais e habilidades educacionais.

Assim, em 28 de agosto de 1986, o Centro Nacional de Educação Especial (Cenesp) lança a Portaria $n^{\circ} 69$ estabelecendo normas para oferecer apoio técnico e financeiro no sistema de ensino do país, incluindo as instituições públicas e particulares. A partir dessa Portaria, tem início uma mudança na Educação Especial, pois esta agora se torna parte integrante da educação nacional e com objetivos que ampliam 
o desenvolvimento das potencialidades dos, a partir daí, chamados "educandos com necessidades especiais" e não mais excepcionais.

Aparece aí, pela primeira vez, a expressão "educando com necessidades especiais" em substituição à expressão "aluno excepcional", que, daí pra frente, é praticamente abolida dos textos oficiais. Todavia, a nova expressão surge mais como eufemismo do que, propriamente, como fruto de nova compreensão da clientela da educação especial. (MAZZOTTA, 2011, p. 81).

Outro ponto importante a ser destacado desta Portaria 69/86 é a especificidade do termo "especializado" na expressão "atendimento educacional especializado", pois a sua significação começa a seguir os princípios de "participação, integração, normalização, interiorização e simplificação". (KASSAR; RABELO, 2011, p. 7). O que justifica também as mudanças ocorridas ao longo do tempo, avançando nos termos técnicos a fim de mostrar um aprimoramento de novas medidas de atendimento aos educandos com necessidades especiais, ou seja, as pessoas começam a ser vistas como educandas e não mais como excepcionais e à margem da sociedade.

Este novo contexto da educação de forma especializada ganha mais espaço, também, em virtude da cooperação entre profissionais de diversas áreas que começam a dialogar mais a fim de realizar um trabalho conjunto, pois enquanto o/a médico/a, psicólogo/a dão laudas aos alunos e às alunas com deficiências, os/as professores/ as tentam trabalhar suas necessidades e potências educacionais baseadas em suas especificidades.

Assim, o Atendimento Educacional Especializado (AEE), de acordo com Mônica Kassar e Andressa Rabelo (2011, p. 7) "consiste na utilização de métodos, técnicas, recursos e procedimentos didáticos desenvolvidos nas diferentes modalidades de atendimento por pessoal devidamente qualificado".

Com os avanços da Educação Especial e já com algumas de suas novas nomenclaturas, no dia 5 de outubro de 1988, é promulgada a nova Constituição Brasileira que, por sua vez, apresenta em seu conteúdo direitos e garantias para as pessoas com deficiências, transtornos globais do desenvolvimento, altas habilidades e/ou superdotação.

[...] a Constituição Federal de 1988 garante atendimento educacional especializado aos portadores de deficiência, preferencialmente na rede regular de ensino. [...] Na década de 1990, percebe-se uma preocupação de se identificar a educação especial a um olhar pedagógico/educacional e escolar. Nesse período temos a influência das concepções difundidas por organismos multilaterais no corpo das formulações das políticas educacionais brasileiras [...]. (KASSAR; RABELO, 2011, p. 7-8).

No artigo 206 da Constituição, fica evidenciada uma das premissas da Educação Especial que é a igualdade de oportunidades, de condições para acesso e 
DAMASCENO, JCB; ASSUMPÇÃO, DJF. Uma reflexão da educação especial a partir das políticas públicas educacionais brasileiras. Revista @mbienteeducação. São Paulo: Universidade Cidade de São Paulo, v. 13, n. 2, p. 216-231 Mai/Ago 2020.

permanência na escola (BRASIL, 1988). "Este princípio assinalou a necessidade de expansão da educação pública e gratuita ao sujeito com deficiência. [...] asseverou como dever Estatal prover atendimento educacional especializado". (ALVES, 2014, p. $68)$.

Além do artigo 206, a Constituição de 1988 apresenta outros artigos que mostram uma preocupação maior com a Educação Especial, mesmo porque o novo contexto social e político garantia que a Educação avançasse em seus preceitos. Não havia mais ditadura militar e a consciência política dos movimentos populares se tornava mais forte, ampliando os espaços de participação social e de luta.

Esses outros artigos são: Artigo 203, que dispõe sobre a assistência social, pois no seu inciso IV fala da habilitação e reabilitação das pessoas portadoras de deficiência; e no inciso $\mathrm{V}$, fala sobre a garantia de um salário mínimo de benefício mensal à pessoa portadora de deficiência. Artigo 205, garante que a educação é direito de todos e dever do Estado. Artigo 208, inciso III, apresenta o atendimento educacional especializado aos portadores de deficiência, preferencialmente na rede regular de ensino. Artigo 227, parágrafo $1^{\circ}$, diz que serão criados programas de prevenção e atendimento especializado para os portadores de deficiência física, sensorial ou mental.

E este avanço pode ser percebido na Lei $n^{\circ} 7.853$ de 1989, pois ela estabeleceu normas gerais para o pleno exercício dos direitos individuais e sociais das pessoas portadoras de deficiência e sua efetiva integração social. Apesar de em alguns momentos utilizar a palavra "integração", a Lei, em seu texto, apresenta, a palavra "inclusão", que também começa a ser usada nos textos oficiais.

Essa Lei reestruturou a Coordenadoria Nacional para a Pessoa Portadora de Deficiência (Corde) que se tornou um órgão autônomo financeiramente, dando mais possibilidades de ações para as pessoas com deficiência. Além disso, apresentou a necessidade de reestruturar, também, a Secretaria de Educação Especial (SESPE) que, mais tarde, em 1990, se tornou a nova Secretaria Nacional de Educação Básica (SENEB). Esse fato fez com que a Educação Especial e a Educação Básica se tornassem competências da SENEB.

Em 1990, outro marco importante para a Educação Especial foi a efetivação do Estatuto da Criança e do Adolescente (ECA), estabelecido pela Lei $n^{\circ} 8.069$. Mazzotta (2011, p. 88) ressalta que

[...] este Estatuto é o conjunto de direitos e deveres legalmente estabelecidos para toda criança e adolescente, portador (a) de deficiência ou não. No que se refere à criança e ao adolescente portadores de deficiência, essa legislação significa um importante caminho para o exercício de direitos até então presentes em "declarações" genéricas e abstratas, mas muito poucas vezes praticados, por falta de mecanismos eficazes. (MAZZOTTA, 2011, p. 88). 
DAMASCENO, JCB; ASSUMPÇÃO, DJF. Uma reflexão da educação especial a partir das políticas públicas educacionais brasileiras. Revista @mbienteeducação. São Paulo: Universidade Cidade de São Paulo, v. 13, n. 2, p. 216-231 Mai/Ago 2020.

Em 1991, a Resolução $n^{\circ} 01$ é editada pelo Fundo Nacional para Desenvolvimento da Educação (FNDE), a qual "condiciona o repasse do salárioeducação à aplicação, pelos Estados e Municípios, de pelo menos $8 \%$ dos recursos educacionais no ensino especial". (MAZZOTTA, 2011, p. 90). Porém, o aporte financeiro destinado à Educação Especial ficou incipiente em decorrência do Projeto Lei, do então presidente Fernando Collor de Mello, que solicitava ao Congresso a retirada de setenta bilhões de cruzeiros destinados à Educação Especial e à erradicação do analfabetismo e universalização do ensino fundamental.

Nesta época, a Seneb divulgou seu pronunciamento sobre a diminuição dos recursos financeiros destinados à Educação Especial, afirmando que apenas 23\% do seu orçamento foi efetivamente utilizado e que esta porcentagem seria o suficiente para suprir as necessidades das crianças excepcionais - nomenclatura adotada pelo referido órgão público.

Atente-se, também, para o fato de que a burocracia do MEC, muitas vezes, somente viabiliza o repasse de tais recursos em época que dificulta ou impossibilita a tão necessária aplicação. Liberada, às vezes, em novembro ou dezembro, seu destino mais fácil passa a ser a devolução. (MAZZOTTA, 2011, p. 92).

Avançando um pouco mais nos atos legais, temos a versão atual da LDB 9.394/96, diferente das duas versões anteriores por ter sido constituída com uma maior participação popular e não mais no contexto político, social e educacional da ditadura militar.

Apresenta em seu conteúdo o Capítulo $V$ que trata sobre a Educação Especial, e nele podemos perceber uma preocupação com os serviços especializados para a demanda específica, com o sistema de ensino dos alunos e das alunas com necessidades educacionais especiais, preocupação com acesso igualitário aos benefícios dos programas sociais suplementares disponíveis para o respectivo nível do ensino regular. Além disso, pela LDB 9.394/96, o poder público deveria ampliar o atendimento aos educandos e às educandas com deficiência, transtornos globais do desenvolvimento e altas habilidades e/ou superdotação.

No início dos anos 2000, a ampliação dos espaços de lutas e de participação popular das pessoas com deficiências colaborou para que novas mudanças na Educação Especial acontecessem. Uma delas foi a emancipação da perspectiva inclusiva, que começou a ganhar forças no sistema de ensino do país, como garante a Resolução CNE/CEB n² 2/2001, que instituiu as Diretrizes Nacionais para a Educação Especial na Educação Básica.

$\mathrm{O}$ artigo $2^{\circ}$ define que os sistemas de ensino devem garantir as matrículas de todos os alunos e de todas as alunas, e as escolas, por sua vez, devem se adaptar 
DAMASCENO, JCB; ASSUMPÇÃO, DJF. Uma reflexão da educação especial a partir das políticas públicas educacionais brasileiras. Revista @mbienteeducação. São Paulo: Universidade Cidade de São Paulo, v. 13, n. 2, p. 216-231 Mai/Ago 2020.

para recebê-los/as e atendê-los/as com condições necessárias para oportunizar uma educação de qualidade. (XAVIER; ROCHA JR., 2018)

Em 2007, foi divulgada a Portaria Normativa $n^{\circ} 13$, que dispõe sobre a criação do Programa de Implantação de Salas de Recursos Multifuncionais. O programa tinha a proposta de ofertar às escolas públicas de ensino regular recursos pedagógicos que pudessem contribuir para o AEE.

\begin{abstract}
A relevância ao funcionamento das salas de recursos deve-se ao fato de que elas assumem um papel de suplementação e complementação pedagógica nos processos de inclusão escolar. Elas introduzem a Educação Especial nas escolas comuns para se associar à educação geral e não para substituíla. São espaços privilegiados para desenvolver estratégias pedagógicas que possam potencializar as capacidades e as condições dos alunos com deficiências para se envolverem nos processos de ensino na sala de aula comum. (RIGO, 2016, p. 193).
\end{abstract}

Eram oferecidos equipamentos de informática, mobiliários, materiais pedagógicos que pudessem ser usados em um espaço de atendimento educacional especializado chamado de "Salas de Recursos Multifuncionais".

Dessa forma, muitos avanços aconteceram deste a primeira promulgação da LDB, mas também percalços como a ditadura militar. Porém, à medida que a sociedade ia sofrendo mudanças as políticas públicas também e, hoje, como resultado de uma dessas transformações temos a PNEEPEI que tem como principal proposta acompanhar os avanços do conhecimento e das lutas sociais, com a possibilidade de elaborar políticas públicas em prol de uma educação de qualidade para todos os/as alunos/as.

\title{
MUDANÇAS NA POLÍTICA NACIONAL DE EDUCAÇÃO ESPECIAL PELA PERSPECTIVA DA EDUCAÇÃO INCLUSIVA
}

Em 2008, foi elaborado um dos mais importantes documentos oficiais referentes à Educação Especial do país, a PNEEPEI. "Essa Política está desafiando e mobilizando os sistemas de ensino estaduais e/ou municipais a organizarem políticas locais que atendam às suas diretrizes." (RIGO, 2016, p. 189).

O referido documento foi elaborado por um Grupo de Trabalho baseado em aspectos técnicos e pela participação popular que refletia a demanda social, com o objetivo de discutir e delimitar propostas pedagógicas que pudessem colaborar para o desenvolvimento da Educação Especial pela perspectiva Inclusiva nas escolas brasileiras. Porém, foi a participação popular a maior propulsora da constituição desta Política, pois foram os anseios e necessidades educacionais das pessoas com deficiência e das pessoas que estão diretamente relacionadas a esta questão que impulsionaram a elaboração deste documento. 
Os movimentos sociais das pessoas com deficiências foram fundamentais para que essa minoria fosse ouvida e que tivesse mais espaços e participação coletiva nas formulações das políticas públicas. Afinal, são eles os sujeitos capazes de dizer quais as suas reais necessidades na área educacional.

\begin{abstract}
Percebemos um grande interesse da Política Nacional em mostrar resultados das ações, os indicadores, as estimativas, enfim, uma preocupação que busca atender aos princípios de uma política global, a qual estabelece linhas de ações compensatórias, na qual os alunos que nunca tiveram acesso à escola regular, agora terão a possibilidade de ser matriculados na escola e ocupar um espaço dentro das salas comuns. (ALMEIDA, 2010, p. 79).
\end{abstract}

O resultado das discussões populares, orientações e propostas feitas, também, pelo Grupo de Trabalho gerou um documento oficial de estado que permite compreender como a Educação Especial no Brasil se desenvolveu ao longo do tempo e as perspectivas que ela traz aos alunos e às alunas, responsáveis e profissionais da área de educação. $O$ documento foi entregue ao Ministro da Educação (MEC) no dia 7 de janeiro de 2008.

\begin{abstract}
Desta forma, a inclusão escolar impulsionada pela atual política nacional defende que as crianças com deficiências sejam matriculadas nas escolas comuns. Ela propõe, positivamente, retirar as crianças do isolamento ou do convívio privado com seus iguais (em classes especiais), para colocálas diante da necessidade da vida social na diversidade (em salas de aula comuns). Não basta, entretanto, que elas estejam lá. Por isso, a política nacional soma duas possibilidades - sala do AEE e sala de aula comum para que a criança com deficiência vivencie experiências culturais e sociais, seja em momentos individualizados ou coletivos de aprendizagem. (RIGO, 2016, p. 194).
\end{abstract}

Diante disso, percebemos que a Política Nacional de Educação Especial está inserida em um contexto histórico e social que nos permite perceber que seu texto foi construído com base nas políticas públicas já decretadas, bem como baseada nos movimentos sociais.

\begin{abstract}
A política de Educação Especial tem-se efetivado do ponto de vista de garantia de acesso dos alunos público-alvo do atendimento especializado ao ensino regular; no entanto, nesse cenário de inclusão escolar, oferecer subsídios que venham fortalecer o trabalho do professor ainda carece de resultados efetivos. Apenas a inserção de disciplinas que discutem a Educação Especial nas licenciaturas mostra-se como prática insuficiente. (TORRES; MENDES, 2019, p. 766).
\end{abstract}

Assim, ao refletir sobre a Política Nacional de Educação Especial pela Perspectiva da Educação Inclusiva faz com que se perceba como um ideário político influencia direta e indiretamente nas ações e atividades dos professores e das professoras, nas metodologias de ensino adotadas nas escolas, no trabalho do corpo técnico das instituições escolares e, principalmente, no desenvolvimento educacional 
DAMASCENO, JCB; ASSUMPÇÃO, DJF. Uma reflexão da educação especial a partir das políticas públicas educacionais brasileiras. Revista @mbienteeducação. São Paulo: Universidade Cidade de São Paulo, v. 13, n. 2, p. 216-231 Mai/Ago 2020.

dos alunos e das alunas público-alvo do AEE, interferindo no seu processo de aprendizagem escolar e no seu processo como um sujeito em sociedade.

Por essa razão, o que se espera do AEE não é um trabalho de normalização do aluno com deficiências, mas uma oportunidade para que ele possa impulsionar seu desenvolvimento por meio de estratégias pedagógicas específicas, que the permitam investimentos nas condições das suas funções psicológicas superiores (controle consciente do pensamento, atenção, memória, abstração, raciocínio dedutivo, etc.). (RIGO, 2016, p. 193).

Porém, em 2018, 10 anos após a elaboração dessa Política, o MEC, por meio da Secretaria de Educação Continuada, Alfabetização, Diversidade e Inclusão (Secadi), decidiu realizar uma consulta pública a fim de atualizar o documento com o objetivo de apontar possíveis lacunas em seu conteúdo, propor melhorias de cunho pedagógico, bem como inserir uma nova Política Nacional de Educação Especial que se adequasse ao novo contexto político e educacional que o país começara a se desenvolver.

Assim, diferentemente da primeira versão, desde abril de 2018, a Política Nacional de Educação Especial passa por um processo de atualização que já contou com o surgimento de alguns espaços de fala, como a consulta pública realizada no período de 6 a 23 de novembro de 2018 e com a audiência pública ocorrida no dia 19 de novembro de 2018.

Tais eventos serviram para ouvir pais, mães, responsáveis, alunos, alunas, professoras/es, instituições de ensino, profissionais afins e sociedade em geral sobre os processos que imbricam a Educação Especial no país. Tanto a audiência pública quanto a consulta pública coletaram sugestões, críticas e opiniões (o documento com essas informações está disponível no site do $\mathrm{MEC}^{3}$ ).

A Universidade Federal de Alagoas, por meio do Núcleo de Excelência em Tecnologias Sociais (NEES) do Centro de Educação, coordenado pelo professor doutor Leonardo Brandão Marques, é a responsável por coletar e organizar essas informações para a atualização da Política e produzir o relatório final. O NEES já realizou, também, encontros técnicos com especialistas da área para colaborar com este processo. Porém, a finalização da atualização do documento ainda não foi efetivada. Diante dessa condição, a Política ainda em vigor oficialmente é a da primeira versão de 2008.

3 Disponível em: https://pnee.mec.gov.br/dados_consulta/Minuta_PNEE_2018_RelatorioContribuicoes.pdf. Acessado em: 24/04/2020. 
DAMASCENO, JCB; ASSUMPÇÃO, DJF. Uma reflexão da educação especial a partir das políticas públicas educacionais brasileiras. Revista @mbienteeducação. São Paulo: Universidade Cidade de São Paulo, v. 13, n. 2, p. 216-231 Mai/Ago 2020.

\section{CONSIDERAÇÕES FINAIS}

O percurso histórico das políticas públicas da Educação Especial no Brasil foi discutido para entender os desenvolvimentos das políticas públicas no âmbito da educação especial pela perspectiva inclusiva e como o desenvolvimento e constituições dos processos educativos e pedagógicos foram acontecendo e ainda estão acontecendo na sociedade.

Foi considerado, também, como o contexto social e político interferiu na educação do país e como os movimentos sociais e populares interferiram e influenciaram, direta e indiretamente, no avanço do processo inclusivo nas escolas comuns e a importância das escolas especializadas para um atendimento direcionado aos alunos e às alunas que apresentam alguma deficiência, transtornos globais do atendimento e altas habilidade e/ou superdotação.

As alterações da LDB e as mudanças atuais da PNEEPEI também foram apontadas, de modo que os dois documentos têm sido usados para referenciar a educação especial pela perspectiva inclusiva e incitar novas propostas e novos olhares para o processo de ensino-aprendizado.

Assim, essa pesquisa deixa ainda aberto para uma ampliação desse debate em uma esfera prática. Pois nota-se que, mesmo com as diretrizes e políticas estabelecidas, há desafios de implementação, aplicação e conscientização do estado, da escola e da sociedade como um todo.

\section{REFERÊNCIAS}

ALMEIDA, Welita Gomes de. Reflexões sobre as políticas de inclusão na educação brasileira. V Congresso Nacional de Educação. Disponível em: http://www. editorarealize.com.br/revistas/conedu/trabalhos/TRABALHO_EV117_MD1_SA10_ ID5233_09092018230308.pdf. Acessado em: 21/04/2020.

ALVES, Denise Soares da Silva. Uma análise da implementação da política nacional de educação especial na perspectiva da educação inclusiva no município de Jundiaí, SP. Dissertação apresentada ao Programa de Pós-Graduação em Educação da Faculdade de Educação da Universidade Estadual de Campinas. 2014. Disponível em: http://repositorio.unicamp.br/bitstream/REPOSIP/254157/1/ Alves_DeniseSoaresdaSilva_M.pdf. Acessado em: 21/04/2020.

CLANDININ, D. Jean. CONELLY, F. Michael. Pesquisa narrativa: experiências e história na pesquisa qualitativa. Tradução: Grupo de Pesquisa Narrativa e Educação de Professores ILEEL/UFU. Uberlândia: EDUFU, 2011. 
DAMASCENO, JCB; ASSUMPÇÃO, DJF. Uma reflexão da educação especial a partir das políticas públicas educacionais brasileiras. Revista @mbienteeducação. São Paulo: Universidade Cidade de São Paulo, v. 13, n. 2, p. 216-231 Mai/Ago 2020.

BRASIL. Ministério da Educação. Lei de Diretrizes e Bases da Educação Nacional, LDB 4.024, de 20 de dezembro de 1961. Disponível em: http://www.planalto.gov.br/ ccivil_03/leis/L4024.htm. Acessado em: 21/04/2020.

BRASIL. Ministério da Educação. Lei de Diretrizes e Bases da Educação Nacional, LDB 5.692, de 11 de agosto de 1971. Disponível em: http://www.planalto.gov.br/ ccivil_03/leis/15692.htm. Acessado em: 21/04/2020.

BRASIL, Ministério da Educação. Portaria Interministerial $n^{\circ} 477$ de 11 de agosto de 1977. Disponível em: https://www.camara.leg.br/proposicoesWeb/prop_ mostrarintegra;jsessionid=81F1872FEA23E5C7068F6BCDFC856F05. node1 codteor $=1184512 \&$ filename=Avulso+-PL+4186/1977. Acessado em: 21/04/2020.

BRASIL. MEC/MPAS. Portaria Interministerial $n^{\circ}$ 186, de 10 de março de 1978. Brasília, DF.

BRASIL. Ministério da Educação. Lei $\mathbf{n}^{\circ} 7.044$ de 18 de outubro de 1982. Disponível em: http://www.planalto.gov.br/ccivil_03/leis/L7044.htm. Acessado em: 21/04/2020.

BRASIL. Ministério da Educação e Cultura. Centro Nacional de Educação Especial. Portaria CENESP/MEC $n^{\circ}$. 69, de 28 de agosto de 1986. Diário Oficial [da República Federativa do Brasil], Brasília, DF, 1986.

BRASIL. Constituição da República Federativa do Brasil. Brasília: Imprensa Oficial, 1988. Disponível em: http://www.planalto.gov.br/ccivil_03/constituicao/constituicao. htm. Acessado em: 21/04/2020.

BRASIL. Ministério da Educação. Secretaria de Educação Especial. Lei No. 7.853, de 24 de outubro de 1989. Disponível em: http://www.planalto.gov.br/ccivil_03/leis//7853. htm. Acessado em: 21/04/2020.

BRASIL. Estatuto da Criança e do Adolescente no Brasil. Lei n. 8.069, de 13 de julho de 1990. Disponível em: http://www.planalto.gov.br/ccivil_03/leis//8069.htm. Acessado em: 21/04/2020.

BRASIL. Ministério da Educação. Resolução nº 01 de 1991 - FNDE.

BRASIL. Ministério da Educação. Lei de Diretrizes e Bases da Educação Nacional, LDB 9.394, de 20 de dezembro de 1996. Disponível em: http://www.planalto.gov.br/ ccivil_03/leis/19394.htm. Acessado em: 21/04/2020. 
DAMASCENO, JCB; ASSUMPÇÃO, DJF. Uma reflexão da educação especial a partir das políticas públicas educacionais brasileiras. Revista @mbienteeducação. São Paulo: Universidade Cidade de São Paulo, v. 13, n. 2, p. 216-231 Mai/Ago 2020.

BRASIL. Ministério da Educação. Secretaria de Educação Especial. Diretrizes Nacionais para a Educação Especial na Educação Básica. Secretaria de Educação Especial - MEC/SEESP, Resolução $n^{\circ} 02$ de 2001. Disponível em: http://portal.mec. gov.br/seesp/arquivos/pdf/diretrizes.pdf. Acessado em: 21/04/2020.

BRASIL. Ministério da Educação. Secretaria de Educação Especial. Portaria Normativa $n^{\circ}$ 13, de 24 de abril de 2007. Disponível em: http://portal.mec.gov.br/ index.php?option=com_docman\&view=download\&alias=9935-portaria-13-24-abril2007\&ltemid=30192. Acessado em: 21/04/2020.

BRASIL, Política Nacional de Educação Especial pela Perspectiva Inclusiva. 2008. Disponivel em: http://portal.mec.gov.br/index.php?option=com_docman\&task=doc_ download\&gid=16690\&ltemid=. Acessado em 21/04/2020.

KASSAR, Mônica de Carvalho Magalhães; REBELO, Andressa Santos. O "especial" na educação, no atendimento especializado e a educação especial. In: VI Seminário Nacional de Pesquisa em Educação Especial, realizado em Nova Almeida-Serra/ ES, de 11 a 13 de abril de 2011. Realização: UFes, UFGRS e UFScar. Disponível em: http://ppeees.ufms.br/wp-content/uploads/2015/02/M\%C3\%B4nica-Kassar-EAndressa-Rebelo-SNPEE.pdf. Acessado em: 21/04/2020.

MATOS, Selma Norberto; MENDES, Enicéia Gonçalves. A proposta de inclusão escolar no contexto nacional de implementação das políticas educacionais. Práxis Educacional. Vitória da Conquista. v. 10, n. 16 p. 35-59 jan./jun. 2014. Disponível em: https://pdfs.semanticscholar.org/7e80/9ed93d602c51e7e4d8a4a8a7ce93cc0087cb. pdf. Acessado em: 21/04/2020.

MAZZOTTA, Marcos. J. S. Educação Especial no Brasil: história e políticas públicas. $6^{a}$ ed. São Paulo/SP: Cortez, 2011.

SÁ-SILVA, Jackson Ronie; ALMEIDA, Cristóvão Domingos de; GUINDANI, Joel Felipe. Pesquisa documental: pistas teóricas e metodológicas. Revista Brasileira de História \& Ciências Sociais. Ano I - Número I - Julho de 2009. Disponível em: https:// www.rbhcs.com/rbhcs/article/viewFile/6/pdf. Acessado em: 15/03/2019.

TORRES, Josiane Pereira; MENDES, Enicéia Gonçalves. Atitudes Sociais e Formação Inicial de Professores para a Educação Especial. Revista Brasileira de educação Especial, vol.25 no.4 Bauru Oct./Dec. 2019 Epub Nov 25, 2019. Disponível em: http://www.scielo.br/scielo.php?pid=S1413-65382019000400765\&script=sci arttext\&tIng=pt. Acessado em: 21/04/2020. 
DAMASCENO, JCB; ASSUMPÇÃO, DJF. Uma reflexão da educação especial a partir das políticas públicas educacionais brasileiras. Revista @mbienteeducação. São Paulo: Universidade Cidade de São Paulo, v. 13, n. 2, p. 216-231 Mai/Ago 2020.

TORRES, Josiane Pereira; MENDES, Enicéia Gonçalves. Formação de professores de ciências exatas numa perspectiva inclusiva. Revista Insignare Scientia - RIS, 1(3), 1-21, 2018. Disponível em: https://periodicos.uffs.edu.br/index.php/RIS/article/ view/10596. Acessado em: 21/04/2020.

XAVIER, Lázaro Rodrigues; ROCHA JÚNIOR, Fernando Leitão. Políticas públicas voltadas para educação especial e inclusiva no Brasil. 2018. Disponível em: https:// www.webartigos.com/artigos/politicas-publicas-voltadas-para-educacao-especial-einclusiva-no-brasil/159590. Acessado em: 21/04/2020.

\section{SOBRE OS AUTORES}

JOÃO CARLOS BITTENCOURT DAMASCENO. Mestre em Educação pelo Programa de Pós-Graduação em Educação do Centro Universitário Salesiano de São Paulo UNISAL (2019). Especialização em Educação Especial pela Faculdade Ipiranga (2013). Graduação em Licenciatura Plena em Ciências Naturais - Física pela Universidade Estadual do Maranhão (2007). Graduação em Pedagogia pela Universidade Cidade de São Paulo- UNICID (2016). Atualmente é professor efetivo da Secretaria de Estado de Educação do Pará (Seduc) e da Secretaria Municipal de Educação de Ananindeua (Semed).

DOUGLAS JUNIO FERNANDES ASSUMPÇÃO. Pós-Doutor pelo Programa de Pósgraduação em Comunicação, Linguagens e Cultura da Universidade da Amazônia -UNAMA(2020). Doutor pelo Programa de Comunicação e Linguagens pela Universidade Tuiuti do Paraná - UTP (2018), e mestre pelo Programa de Comunicação, Linguagens e Cultura pela Universidade da Amazônia - UNAMA (2013). Possui graduação em Comunicação Social - habilitação em Multimídia (2010) e Relações Públicas (2012) pelo Instituto de Estudos Superiores da Amazônia - IESAM, (atual Faculdade Estácio de Belém ), e Graduado em Comunicação Social - habilitação em Jornalismo (2017) pela Universidade da Amazônia - UNAMA, é especialista em Comunicação Empresarial pela Faculdade da Amazônia - FAAM (2011). Atualmente é professor da Escola Superior Madre Celeste (ESMAC) nos cursos de Bacharelado em Administração, Ciências Contábeis e Licenciatura em Letras É Vice-Líder do Grupo de Pesquisa (GP) Estudos de Capital Social e Cultural no contexto da mídia contemporânea (UNAMA/CNPq), membro do GP Journalisme à l? heure du numérique - JAND (Université Lumiré Lyon 2 / Lyon - França) e GP ECCOS - Estudos sobre Comunicação, Consumo e Sociedade (UFPR/CNPq) Tem experiência na área de Comunicação, com ênfase em Relações Públicas,Jornalismo e Multimeios atuando principalmente nos seguintes temas: Comunicação organizacional, Comunicação 


\section{REVISTA @imbienteeducação}

DAMASCENO, JCB; ASSUMPÇÃO, DJF. Uma reflexão da educação especial a partir das políticas públicas educacionais brasileiras. Revista @mbienteeducação. São Paulo: Universidade Cidade de São Paulo, v. 13, n. 2, p. 216-231 Mai/Ago 2020.

e Marketing digital, Comunicação e Consumo, Novas Tecnologias e Processo de Criação.

RECEBIDO: 30/04/2020.

APROVADO: $13 / 05 / 2020$. 